\title{
REFLEXÕES SOBRE REFERENCIAIS DE QUALIDADE PARA EDUCAÇÃO SUPERIOR A DISTÂNCIA: CONTEMPLAR SEUS INDICADORES GARANTE A QUALIDADE?
}

\author{
SÃO PAULO/SP JUNHO/2018 \\ $\begin{array}{cl}\text { TATSUO IWATA NETO } & \text { - ESPM - tatsuo@espm.br } \\ \text { VIVIAN VAZ BATISTA ALVES } & \text { - PUC-SP - vivian.vvb@hotmail.com }\end{array}$ \\ Tipo: Investigação Científica (IC) \\ Natureza: Relatório Final de Pesquisa \\ Categoria: Pesquisa e Avaliação \\ Setor Educacional: EDUCAÇÃO SUPERIOR
}

\begin{abstract}
RESUMO
Este trabalho é um recorte da pesquisa realizada durante o mestrado pelos autores sobre a temática e apresenta reflexões sobre a qualidade de cursos na modalidade a distância, tendo como parâmetro os Referenciais de Qualidade para Educação Superior a Distância (2007) e a experiência vivida pelos autores desse trabalho enquanto coordenadores e professores de cursos na modalidade a distância de Formação de Professores e de Educação Corporativa. A modalidade de Educação a Distância, caracterizada pelo uso de tecnologias de informação e comunicação (TIC), em que professores e alunos estão separados fisicamente no espaço e/ou no tempo, a cada ano vem crescendo nos diferentes níveis de Educação, como uma ferramenta de promoção de oportunidades para muitas pessoas. Nos Referenciais de Qualidade para Educação Superior a Distância são apresentados princípios, diretrizes e critérios para instituições que ofereçam cursos na modalidade a distância. Mas será que levar em conta indicadores de qualidade apresentados nos Referenciais de Qualidade para o Ensino Superior a Distância (2007) garante a qualidade do curso? Para o desenvolvimento dessa pesquisa adotou-se como metodologia a pesquisa qualitativa e como procedimento, a reflexão sobre os Referenciais de Qualidade para Educação Superior a Distância e a própria prática experimentada e vivida. Para além de contemplar os indicadores, a qualidade está ligada a uma complexidade de fatores ligados à concepção de educação, a quem se quer formar, perfil dos alunos, perfil dos professores, tutores, coordenadores, metodologia, recursos pedagógicos, infra-estrutura, gestão financeira.
\end{abstract}

Palavras-chave: Educação a Distância. Referencias de Qualidade. Gestão Educacional. 


\section{Introdução}

Este trabalho é um recorte da pesquisa realizada durante o mestrado pelos autores sobre a temática e tem por objetivo apresentar reflexões sobre qualidade de curso na modalidade a distância a partir de experiência vivida como coordenadores e professores de curso de Formação de Professores e Educação Corporativa, assim como coordenadores de Polo de uma Universidade privada da cidade de São Paulo. O interesse pela temática emerge da experiência dos pesquisadores que têm se questionado a respeito da garantia da qualidade de seus cursos:

A modalidade de Educação a Distância, caracterizada pelo uso de tecnologias de informação e comunicação (TICs), em que professores e alunos estão separados fisicamente no espaço e/ou no tempo, a cada ano vem crescendo como uma ferramenta de promoção de oportunidade para muitas pessoas poderem continuar seus estudos em nível de Ensino Superior. Segundo Gatti (2014) pode-se evidenciar que há uma diferença entre as modalidades de ensino presencial e a distância referentes a bacharelados e licenciaturas. Conforme a autora, neste estudo, em 2014, em graduação presencial $73 \%$ são matrículas em bacharelados e 16,1\% em licenciaturas. Enquanto que na graduação a distância 43,3\% das matrículas estão nas licenciaturas e 30\%, em bacharelados. Esses números continuam aumentando, conforme Censo da Educação Superior 2016: O número de matrículas em cursos de graduação presencial diminuiu 1,2\% entre 2015 e 2016; na modalidade a distância, o aumento foi de 7,2\%. A participação da educação a distância em 2006 era de 4,2\% do total de matrículas em cursos de graduação e aumentou sua participação em 2016 para 18,6\% (BRASIL, 2016, p. 7).

Voltando-se para o contexto profissional dos pesquisadores surge o problema da pesquisa na proposta do EaD, em especial do curso de Formação de Professores e de Educação Corporativa de uma universidade privada de São Paulo, que questiona se os indicadores de qualidade apresentados nos Referenciais de Qualidade para o Ensino Superior a Distância (2007) garantem a qualidade do curso? Diante da expansão de matrículas em cursos na modalidade a distância, conforme Censo da Educação Superior 2016 (INEP 2016) e Gatti (2014) e considerando esforços do governo, por meio de documentos para regular e estabelecer condições que garantam a qualidade dos cursos de formação de professores à distância, a presente pesquisa pretende trazer elementos para reflexão sobre possíveis contribuições dos Referenciais de Qualidade do Ensino Superior a Distância para os cursos nessa modalidade.

Para o desenvolvimento dessa pesquisa adotou-se como metodologia a pesquisa 
qualitativa e como procedimento, reflexão sobre os Referenciais de Qualidade para Educação Superior a Distância e a própria prática experimentada e vivida. Segundo Moore e Kearsley (2007), a Educação a Distância baseia-se no aprendizado planejado que ocorre normalmente em espaço diferente do lugar de ensino convencional. Para essa modalidade de ensino, conforme os autores, são exigidas técnicas especiais de criação do curso e de instrução, comunicação, por meio de diferentes tecnologias e disposições organizacionais e administrativas especiais. Os autores, Moore e Kearley (2007) quando comentam que para a EaD são exigidas "técnicas especiais" chama a atenção para um fator muito importante na Educação a Distância que é a criatividade: fazer uso de diferentes tecnologias que, geralmente, é comum nos cursos de EaD como, vídeos, gravações de som, imagens, possibilidade de acesso a livros no formato e-book tornam o ambiente virtual mais atrativo. Porém, não são suficientes tais recursos e podese até afirmar, conforme experiência dos autores, que o mais importante é a interação professor/tutor-aluno, a resposta imediata para as questões e dúvidas dos alunos. A falta ou demora de resposta desistimula o estudante, levando-o, muitas vezes, à desistência do curso.

Se se quer uma educação de qualidade, é preciso levar em conta a relação professoraluno na modalidade a distância. Tal relação faz toda a diferença para o envolvimento, comprometimento, interesse e aprendizagem do aluno. É na interação professor-aluno que esse aluno é instigado a refletir sobre o tema estudado, aprofundar seus estudos, ir para além do material disponível em ambiente online. Dái a importância da equipe, coordenador do curso, professor, tutor e até mesmo o coordenador de polo estarem afinados no sentido de terem o mesmo objetivo: dar todo apoio necessário para o aluno se desenvolver e realizar suas atividades, sentindo-se apoiados e não sozinhos no ambiente virtual. $O$ fato de as salas virtuais serem numerosas faz com que, na maioria das vezes, o tutor não consiga responder imediatamente o aluno e isso, quando acontece repetidamente, é um fator que pode levar ao menor aproveitamento do curso e até mesmo ao aumento da evasão. Daí a importância de toda equipe estar atenta e se ajudar. O próprio coordenador de Polo que a princípio teria a função de administrar o Polo e a parte de serviços de secretaria tem também um papel pedagógico, pois muitas vezes ele é procurado para tirar dúvidas pedagógicas, devido à demora da resposta do tutor. Aqui destacamos a missão de nossa instituição quanto ao perfil desejado de egresso assim como o caminho de formação escolhido, dando assim maior atenção ao dimensionamento do número de alunos por professor/tutor.

Dohmem (1967) apud Alves (2011), conceitua Educação a Distância como forma de estudo de modo organizado e sistemático em realizar o estudo e também autônomo. Isto é, torna possível, de forma sistematicamente organizada o auto-estudo, sem a 
necessidade de professor, partindo dos meios de comunicação eficazes e avançados, capazes de vencer qualquer distância. Mais uma vez, vale aqui ressaltar que, conforme experiência dos autores desse estudo, Educação a Distância possibilita o auto-estudo. Mas, isso não dispensa a necessidade do professor. Muito pelo contrário, o professor/tutor precisa se fazer presente para acompanhar as atividades dos alunos, motivando-os e verificando se estão indo pelo caminho certo, avançando, construindo conhecimento e intervindo quando necessário para que possam, de fato, experimentar uma situação educativa e a construção de conhecimento. Chaves (1999) apud Alves (2011) comenta que a característica fundamental na Educação a Distância é que ela se dá quando ensinante e aprendente ficam separados no tempo e espaço. Estudante e professor/tutor ficam separados no "tempo e espaço", mas a interação frequente entre eles diminui essa distância e o recurso de aplicativos como Skype, Hangouts, por exemplo, aproxima-os quando disponibilizados. Apesar do curso ser a distância, a experiência tem evidenciado a necessidade os alunos verem e ouvirem a voz do professor/tutor.

De acordo com os Referenciais de Qualidade para Educação Superior a Distância (2007), a EAD pode ser concebida de diferentes formas, utilizando diferentes linguagens e recursos por não haver um único modelo, e seu desenho e concepção deverá levar em contar as demandas da realidade de quem se quer atingir. Apesar de não se ter um único caminho é importante que seus elaboradores tenham claro como primeiro fundamento para um projeto de EaD, o conceito de Educação, quem querem formar, o currículo vivo e o modo de organização a distância. Segundo os Referenciais, um curso de graduação na modalidade a distância, para ser de qualidade, exige um compromisso institucional com relação às dimensões pedagógica, técnico-científica, econômica e política. Assim, embora a modalidade a distância possua características, linguagem e formato próprios, exigindo administração, desenho, lógica, acompanhamento, avaliação, recursos técnicos, tecnológicos, de infra-estrutura e pedagógicos condizentes, essas características só ganham relevância no contexto de uma discussão política e pedagógica da ação educativa. Disto decorre que um projeto de curso superior a distância precisa de forte compromisso institucional para garantir um processo de formação que contemple a dimensão técnico-científica para o mundo do trabalho e a dimensão política para a formação do cidadão. Devido à complexidade e à necessidade de uma abordagem sistêmica, referenciais de qualidade para projetos de cursos na modalidade a distância devem compreender categorias que envolvam, fundamentalmente, aspectos pedagógicos, recursos humanos e infra-estrutura (BRASIL, 2007, p. 7)

Para dar conta destas dimensões, devem estar integralmente expressos no Projeto 
Político Pedagógico de um curso na modalidade a distância os seguintes tópicos principais: i)Concepção de educação e currículo no processo de ensino e aprendizagem; ii) Sistemas de Comunicação; iii) Material didático; iv) Avaliação; v) Equipe multidisciplinar; vi) Infra-estrutura de apoio; vii) Gestão Acadêmico-Administrativa; viii) Sustentabilidade financeira (BRASIL, 2007, pp.7-8). Tais, tópicos, de acordo com o documento, eles não são isolados, se relacionam e podem se desdobrar em outros subtópicos.

Como relação à "concepção de educação e currículo no processo de ensino e aprendizagem", é chamada a atenção para a importância da opção epistemológica de educação e de todo processo educativo, assim como ter definido quem se quer formar. É a opção espitemológica que irá nortear a organização do currículo de seu desenvolvimento e até mesmo o perfil dos envolvidos no processo de ensino e aprendizagem. Nesse mesmo item, comenta-se a importância do uso inovador da tecnologia, de modo especial, na educação a distância, com o objetivo de proporcionar a construção do conhecimento, a interatividade entre os estudantes, desenvolvimento de trabalhos coletivos e o respeito e reconhecimento de diferentes culturas. Os referenciais também sugerem um currículo interdisciplinar e contextualizado. Um ponto importante destacado nesse documento, é a importância de se contemplar um módulo de ambientação em cursos a distância, por ser uma novidade, geralmente, para o público interessado e que nem sempre teve contato com o próprio computador. Esse módulo introdutório faz diferença na própria acolhida do estudante no ambiente virtual, e que é muito importante para iniciar a criação de vínculo entre o tutor e o estudante, e também para o melhor aproveitamento do próprio curso por ele. No que se refere à recuperação e avaliação, chama a atenção para a importância de se levar em conta as singularidades dos estudantes, o ritmo de aprendizagem diferenciado. Vale aqui ressaltar que esse quesito relacionado a "ritmo de aprendizagem diferenciado" deveria, de fato, ser respeitado, se a intenção é realmente levar em conta as singularidades de cada estudante e proporcionar a todos o acesso, permanência e formação no ensino superior a todos.

No item "Sistemas de Comunicação", os referencias de qualidade referem-se à importância de se garantir a interatividade entre professores, estudantes e tutores para se garantir a qualidade do curso e a permanência desses no programa. A falta de interação pode fazer com que o aluno se sinta sozinho no processo de ensino aprendizagem, podendo levá-lo à desistência do curso. De acordo com os referenciais, a interatividade deve ser contemplada no projeto político-pedagógico do curso.

O item que se refere a "Material didático", apresenta as seguintes diretrizes: O Material 
Didático, tanto do ponto de vista da abordagem do conteúdo, quanto da forma, deve estar concebido de acordo com os princípios epistemológicos, metodológicos e políticos explicitados no projeto pedagógico, de modo a facilitar a construção do conhecimento e mediar a interlocução entre estudante e professor, devendo passar por rigoroso processo de avaliação prévia (pré-testagem), com o objetivo de identificar necessidades de ajustes, visando o seu aperfeiçoamento. Em consonância com o projeto pedagógico do curso, o material didático, deve desenvolver habilidades e competências específicas, recorrendo a um conjunto de mídias compatível com a proposta e com o contexto socioeconômico do público-alvo Brasil, 2007, p. 13). Nesse item é importante ater-se para a avaliação prévia do material didático, com intuito de garantir a qualidade e com o uso de diferentes recursos midiáticos para o desenvolvimen.to de habilidades e competências específicas nos estudantes.

No que diz respeito à avaliação, as diretrizes sugerem que sejam consideradas no projeto de educação a distância a avaliação da aprendizagem contínua e a avaliação institucional, da qual todos todos devem participar: Com relação à equipe multidisciplinar, a educação a distância permite várias configurações que devem contemplar funções de planejar, implementar e gerenciar os cursos a distância, para isso, esses profissionais que irão compor a equipe multidisciplinar devem estar sempre se atualizando.

No que se refere à qualificação do professor para atuar na educação a distância, seguem suas principais competências: Em primeiro lugar, é enganoso considerar que programas a distância minimizam o trabalho e a mediação do professor. Muito pelo contrário, nos cursos superiores a distância, os professores vêem suas funções se expandirem, o que requer que sejam altamente qualificados. Em uma instituição de ensino superior que promova cursos a distância, os professores devem ser capazes de: a) estabelecer os fundamentos teóricos do projeto; b) selecionar e preparar todo o conteúdo curricular articulado a procedimentos e atividades pedagógicas; $c$ ) identificar os objetivos referentes a competências cognitivas, habilidades e atitudes; d) definir bibliografia, videografia, iconografia, audiografia, tanto básicas quanto complementares; e) elaborar o material didático para programas a distância; f) realizar a gestão acadêmica do processo de ensino-aprendizagem, em particular motivar, orientar, acompanhar e avaliar os estudantes; g) avaliar-se continuamente como profissional participante do coletivo de um projeto de ensino superior a distância. Além disso, a instituição deve indicar uma política de capacitação e atualização permanente destes profissionais (BRASIL, 2007, p. 20-21).

Com relação à importante função do tutor no processo de ensino e aprendizagem, esse 
deve ser sempre valorizado e bem selecionado. De acordo os Referencias, a definição de tutor é: O corpo de tutores desempenha papel de fundamental importância no processo educacional de cursos superiores a distância e compõem quadro diferenciado, no interior das instituições. O tutor deve ser compreendido como um dos sujeitos que participa ativamente da prática pedagógica. Suas atividades desenvolvidas a distância e/ou presencialmente devem contribuir para o desenvolvimento dos processos de ensino e de aprendizagem e para o acompanhamento e avaliação do projeto pedagógico. Um sistema de tutoria necessário ao estabelecimento de uma educação a distância de qualidade deve prever a atuação de profissionais que ofereçam tutoria a distância e tutoria presencial (BRASIL, 2007, p. 21).

O item referente à infra-estrutura de apoio, comenta a necessidade de investimentos: (VI) Infra-estrutura de apoio; (VII) Gestão acadêmico-administrativa; (VIII) Sustentabilidade Financeira

Apesar de não ter força de lei esse documento, os Referencias de Qualidade, aqui apresentados, servem como guia para subsidiar os processos de regulação, supervisão e avaliação de Ead, assim como a organização de proposta teórico-metodológica da educação a distância e da organização de sistema EaD.

\section{Considerações Finais}

Considerando os Referencias de Qualidade e a experiências vividas dos pesquisadores percebe-se que a falta de interação entre alunos e Professor/tutor, levou à constituição de grupos de estudos para tentarem sanar essa carência, mas ressaltamos que isso não é uma prática comum, precisou o coordeandor de Polo mais uma vez intervir no Pedagógico, sugerindo essa prática e até orientado para que eles utilizassem os recursos midiáticos. Ao encontro dessa afirmação, Almeida e Valente (2012) e Almeida (2014), afirmam que a relação dos alunos com as diferentes mídias e ferramentas tecnológicas os instigam a pesquisar e a construírem webcurrículos, por terem evidenciado que o uso de tais recursos na educação podem ser potencializados com vistas à integrar o currículo e por ser também integrador.

Da mesma forma, ao encontro das reflexões aqui apresentadas, Liberali (2015, p.5) em seus estudos é apoiada por Torres Santomé (1998) que destaca também a necessidade de se integrar a escola com a realidade, para torná-la mais atraente, atualizada e contextualizada. Essas considerações sobre webcurrículos e a importância destacada da educação contextualizada e de se levar em conta as ferramentas digitais e de integrálas no currículo contribuem para um maior envolvimento e comprometimento dos alunos, 
estabelecer vínculo entre eles e assim, diminuir o número de evasão. A experiência dos autores desse trabalho tem demonstrado que muitos estudantes de $\mathrm{EaD}$ chegam a desistir dos cursos pela falta de contato com professores, tutores e até mesmo colegas, muitos relatam que se sentem sozinhos durante o curso sentindo-se, assim, desestimulados.

Ao encontro dessa experiência, Gatti (2002) afirma que os contatos humanos mostramse muito importantes tanto no ensino presencial quanto no ensino a distância. O mesmo fazem Moore, Kearsley (2007) em suas pesquisas que apontam a falta de hábito e aptidões para o estudo como um fator de desistência do curso. No item "Sistemas de Comunicação", os referencias de qualidade referem-se à importância de se garantir a interatividade entre professores estudantes, tutores para se garantir a qualidade do curso e a permanência desses no programa. Neves (2002), no Programa da TV Escola: "Salto para o Futuro" do Ministério da Educação - MEC, comenta que para se fazer um curso em EaD é preciso ser persistente e ser organizado: [...] para muitos, parece ser fácil estudar a distância. Na verdade, não é. Estudar a distância exige perseverança, autonomia, capacidade de organizar o próprio tempo, habilidade de leitura, escrita e interpretação (mesmo pela internet) e, cada vez mais frequente, domínio de tecnologia (NEVES, 2002, p. 5).

Nos Referenciais de Qualidade para o Ensino Superior a Distância é chamada a atenção também para a importância de se levar em conta as singularidades dos estudantes no que se refere à recuperação e avaliação: Importantes também são os mecanismos de recuperação de estudos e a avaliação correspondente a essa recuperação, assim como a previsão de métodos avaliativos para estudantes que tem ritmo de aprendizagem diferenciado (BRASIL, 2007, p. 10). O "ritmo de aprendizagem diferenciado" deve sempre ser respeitado, se a intenção é levar em conta as singularidades de cada estudante e proporcionar a todos o acesso, permanência e formação no ensino superior a todos. Moran (2009), também chama a atenção para a necessidade de levar em conta a realidade dos alunos, o ritmo de aprendizagem deles.

De acordo com Gatti (2002), no texto "Critérios de qualidade a educação a distância exige condições muito diferentes da educação presencial. Com relação ao material didático e de apoio, Gatti (2002) chama a atenção para a importância do cuidado com a qualidade desses, pois a falta de qualidade pode levar também o aluno à desisitência do curso. Gatti (2002) e Moran (2002) chamam a atenção para a importância do papel do tutor e dos encontros presenciais bem planejados. De acordo com Moran (2009), um bom curso é aquele que empolga o aluno, que nos surpreende, nos faz pensar, nos envolve ativamente, que traz contribuições significativas e nos põe em contato com 
pessoas, experiências e ideias interessantes.

Moran et al. (2013) destaca a atenção para a importância do bom formador, dos gestores e o perfil dos alunos para a EaD: alunos curiosos, motivados, facilitam enormemente o processo, estimulam as melhores qualidades do professor, tornam-se interlocutores lúcidos e parceiros de caminhada do professor-educador. Moran et al (2013), assim como Gatti (2002), refere-se também à importância da interatividade, do trabalho coletivo, da interdisciplinaridade, do planejamento.

Conclui-se que cursos de Educação a Distância para terem qualidade, além de contemplarem todos os indicadores e quesitos sugeridos nos Referenciais de Qualidade para o Ensino Superior a Distância é preciso estarem comprometidos mesmo com a Educação, ter claro o que entendem por educação, quem eles querem formar e não somente oferecerem um pacote instrucional, entendido como totalmente autodidático. Esses pacotes são mais vulneráveis à desistência do curso e às dificuldades em dominarem os conteúdos. De acordo com Gatti (2002) esse tipo de programa instrucional dificilmente poderia ser reconhecido como educacional, por não propiciar ao aluno a possibilidade de uma adesão consciente e voluntária no processo de aprendizagem proposto, da visão de totalidade. Cursos na modalidade a distância, segundo Gatti (2002) devem proporcionar aos alunos a produção de conhecimento, a pesquisa, a pró-atividade, a reflexão sobre o conteúdo, levando em conta sua realidade e proporcionando a interdisciplinaridade.

Com essa pesquisa, as autores acreditam ter trazido elementos para reflexão sobre possíveis contribuições dos Referenciais de Qualidade do Ensino Superior a Distância para qualidade dos cursos de Formação de Professores, ressaltando que, apenas contemplar tais quesitos de qualidade não é suficiente, a qualidade está ligada a uma complexidade de fatores ligados à concepção de educação, a quem se quer formar, perfil dos alunos, perfil dos professores, tutores, coordenadores, metodologia, recursos pedagógicos, infra-estrutura, gestão financeira.

\section{REFERÊNCIAS}

ALMEIDA, M. E. B.; VALENTE, J. A. Integração currículo e tecnologias e a produção de narrativas digitais. Currículo sem Fronteiras , v. 12, n. 3, p. 57-82, set./dez. 2012.

ALMEIDA, M. E. B; ALVES, D. R. M. OSB; LEMOS, S. D. V. Web Currículo: Aprendizagem, pesquisa e conhecimento com o uso de tecnologias digitais. Série @prendendersempre.com. 2. - 1. ed. - Rio de Janeiro: Letra Capital, 2014. 
ALVES, L. Educação a distância: conceitos e história no Brasil e no mundo. RBAAD: Associação Brasileira de Educação a Distância. Vol. 10, 201, pp. 83 a 92 . Disponível em: http://www.abed.org.br/revistacientifica/Revista_PDF_Doc/2011/Artigo_07.pdf.

BRASIL, Ministério da Educação, Instituto Nacional de Estudos e Pesquisas Educacionais Anísio Teixeira. Censo da Educação Superior 2016. Brasília: INEP, 2016.

Disponível

em:

http://download.inep.gov.br/educacao_superior/censo_superior/documentos/2016/notas sobre_o_censo_da_educacao_superior_2016.pdf. Acesso em: 11/05/2018.

GATTI, B. A. A formação inicial para professores da Educação Básica: as icenciaturas.

REVISTA USP. São Paulo, n. 100, p. 33-46, dezembro/janeiro,fevereiro 2013-2014. Disponível em: https://www.revistas.usp.br/revusp/article/viewFile/76164/79909. Acesso em: 10/05/2018.

LIBERALI, F. C.; MAGALHÃES, M. C. C. ; MEANEY, M. C. ; SANTIAGO, C. ; CANUTO, M. ; SANTOS, J. A. A. . Projeto DIGIT-M-ED Brasil: uma proposta de desencapsulação da aprendizagem escolar por meio dos Multiletramentos. Prolíngua (João Pessoa), v. 10, p. 2-17, 2015.

MOORE, M.\& KEARSLEY, G. Educação a Distância: uma visão integrada. Tradução Roberto Galman. São Paulo: Thomson Learning, 2007.

MORAN, J. M. O que é Educação a Distância. Universidade de São Paulo - ECA, 2002. Disponível em: . Acesso em: 09/05/2018.

MORAN, J. M.; MASETTO, Marcos \& BEHRENS, Marilda. Novas tecnologias e mediação pedagógica. 21a edição, Campinas: Papirus, 2013.

NEVES, C. M. C. A educação a distância e a formação de professores. In: Educação a distância na formação de professores. Salto para Futuro. Brasília: TV Escola, 13 a 17 maio 2002. Programa de TV.

TORRES SANTOMÉ, J. T. A educação em tempos de neoliberalismo. Porto Alegre, 2003. 